\title{
Review Article \\ Cellular and Molecular Mechanisms of Arrhythmia by Oxidative Stress
}

\begin{abstract}
Ali A. Sovari
Cardiac Electrophysiology Section, Heart Institute, Cedars Sinai Medical Center, 127 S. San Vicente Boulevard,
\end{abstract} A3308, Los Angeles, CA 90048, USA

Correspondence should be addressed to Ali A. Sovari; alisovari@gmail.com

Received 30 November 2015; Accepted 10 January 2016

Academic Editor: Yi-Gang Li

Copyright (C) 2016 Ali A. Sovari. This is an open access article distributed under the Creative Commons Attribution License, which permits unrestricted use, distribution, and reproduction in any medium, provided the original work is properly cited.

\begin{abstract}
Current therapies for arrhythmia using ion channel blockade, catheter ablation, or an implantable cardioverter defibrillator have limitations, and it is important to search for new antiarrhythmic therapeutic targets. Both atrial fibrillation and heart failure, a condition with increased arrhythmic risk, are associated with excess amount of reactive oxygen species (ROS). There are several possible ways for ROS to induce arrhythmia. ROS can cause focal activity and reentry. ROS alter multiple cardiac ionic currents. ROS promote cardiac fibrosis and impair gap junction function, resulting in reduced myocyte coupling and facilitation of reentry. In order to design effective antioxidant drugs for treatment of arrhythmia, it is essential to explore the molecular mechanisms by which ROS exert these arrhythmic effects. Activation of $\mathrm{Ca}^{2+} / \mathrm{CaM}$-dependent kinase II, c-Src tyrosine kinase, protein kinase $\mathrm{C}$, and abnormal splicing of cardiac sodium channels are among the recently discovered molecular mechanisms of ROS-induced arrhythmia.
\end{abstract}

\section{Scope of the Problem in Treatment of Arrhythmias}

Cardiovascular disorders are the most common cause of death in the United States and most of the developed countries [1]. Ventricular fibrillation (VF) and ventricular tachycardia (VT) are the most common cause of sudden cardiac death (SCD) [2]. Atrial fibrillation (AF), although usually not life threatening, is associated with higher thromboembolism, increased mortality, and high healthcare cost and its incidence is increasing [3-8].

Current therapies for treatment of arrhythmias are antiarrhythmic drugs, catheter ablation, and implantable cardioverter defibrillators (ICDs) for VT/VF. Although these therapies have had some success, they have limitations. Ion channel blockade has important limitations for chronic treatment and prevention of those arrhythmias. For example, the Cardiac Arrhythmia Suppression Trial (CAST) showed that treatment of premature ventricular contractions (PVCs) with class IC antiarrhythmic drugs may increase cardiovascular mortality in patients with myocardial infarction (MI) [9]. Chronic treatment of AF with current antiarrhythmic drugs has not been more effective than a rate control strategy in reducing thromboembolism [10] which may suggest the ineffectiveness of the antiarrhythmic drugs in maintaining the sinus rhythm. Paradoxically, a common adverse effect of all currently available antiarrhythmic drugs is proarrhythmia $[11,12]$. Catheter ablation therapy is based on creating an anatomically fixed lesion in the heart in order to block the reentrant circuit or propagation of the focal activity. Studies using optical mapping of the heart have shown ectopic foci and reentrant circuits are usually multiple and dynamic in complex arrhythmias such as VF and AF [13-15]. Catheter ablation for VT is primarily an adjuvant therapy for reduction of symptoms in patients with ICD [16] and cannot provide a reliable method for prevention of SCD. Defibrillation has shown success in terminating VT/VF. Nevertheless, it does not prevent the occurrence of arrhythmia, and frequent ICD shocks worsen the quality of life and may even increase mortality [16]. ICDs are relatively expensive. A study that evaluated data from multiple randomized clinical trials estimated that the cost of the ICD-related primary prevention of SCD ranged from $\$ 34,000$ to $\$ 70,200$ for each life-year [17]. In addition, about $70 \%$ of the patients who receive an ICD never 
have any appropriate defibrillation and only $30 \%$ of patients with sudden cardiac arrest (SCA) meet current criteria for implantation of ICD [18].

Many of the aforementioned limitations of current therapies for arrhythmia arise from the fact that these therapies do not address the underlying pathophysiology of arrhythmia. A more successful therapeutic approach may arise from targeting upstream pathologies that result in abnormalities in ionic currents and emergence of reentry and focal activity. Oxidative stress, which is an imbalance between production and neutralization of reactive oxygen species (ROS), is an example of a possible upstream therapeutic target. Most clinical risk factors of AF such as hypertension, age, and cardiothoracic surgeries are conditions that are associated with oxidative stress [19]. Serum markers of oxidative stress have been shown to be elevated in patients with AF [2022]. AF in human is associated with a significant reduction in the expression of antioxidant genes as well as a significant increase in the expression of five genes related to ROS, supporting a shift toward prooxidation state in AF [23]. Cardiomyopathy, which is associated with significantly higher risk of VT/VF, is associated with oxidative stress and increased oxidation and carbonylation of proteins [24]. Perfusion of $\mathrm{H}_{2} \mathrm{O}_{2}$ of hearts in the Langendorff setting induces VT/VF and AF [13-15, 25], providing evidence that ROS elevation can be a cause of arrhythmia.

Despite considerable evidence that ROS play an important role in the genesis of arrhythmia, limited clinical studies using conventional antioxidants have shown conflicting results [26]. The biology of ROS is complex and designing an effective antioxidant therapy for arrhythmia requires an in-depth understanding of the cardiac sources of ROS, the ROS molecules structures and properties, triggers of ROS production, and the downstream effects of ROS which result in arrhythmia. The study of mechanisms by which ROS elevation may result in arrhythmia may lead to the discovery of novel therapeutic targets for treatment of arrhythmia.

\section{Oxidative Stress Facilitating Focal Activity and Reentry}

ROS can lead to focal activity. It has been shown that ROS prolong action potential duration (APD) in rat and guinea pig myocytes and induce early afterdepolarizations (EADs) and delayed afterdepolarization (DADs) [27]. Consistent with that finding, ROS has been shown to facilitate ventricular arrhythmia in aged and hypertensive rat hearts mainly via an EAD mechanism $[25,28]$.

ROS can also provide substrate for reentry. One possible mechanism for reentry in oxidative stress is via heterogeneous APD prolongation in which at a moment one area with shorter APD is excitable while the area with prolonged APD is not excitable $[15,25,29]$. In an angiotensin II activation mouse model with elevated ROS levels and in a mitochondrial oxidative stress mouse model conduction velocity $(\mathrm{CV})$ is decreased and inducible VTs are mainly caused by reentry [30-32].

The results from mathematical modeling studies have supported both reentry via decreased in conduction CV and focal activity via EAD/DAD mechanisms for ROS-mediated arrhythmias $[13,33]$. It is not clear in which conditions and at what levels ROS may promote one of the two mechanisms: focal activity and reentry. Nevertheless, ROS can promote both.

\section{Arrhythmogenic Ionic Effects of Oxidative Stress}

ROS elevation affects several ionic currents in cardiomyocytes. The effect of ROS on total and late $\mathrm{Na}^{+}$current is important and can be arrhythmogenic. One of the mechanisms of $\mathrm{H}_{2} \mathrm{O}_{2}$-induced APD prolongation and EAD formation is by promoting an enhanced late sodium $\left(\mathrm{Na}^{+}\right)$current [34]. Ranolazine, a late $\mathrm{Na}^{+}$current blocker, can suppress ROS-mediated EADs and arrhythmia, which suggests a role for the increased late $\mathrm{Na}^{+}$current in the pathogenesis of ROS-mediated arrhythmia [25]. Treatments with $\mathrm{H}_{2} \mathrm{O}_{2}$ and angiotensin II enhance the late $\mathrm{Na}^{+}$current; however, those treatments decrease the overall $\mathrm{Na}^{+}$current in isolated myocytes partially through the downregulation of SCN5A transcription [35]. While an increase in late $\mathrm{Na}^{+}$current may result in arrhythmia via an EAD mechanism, the reduction in total $\mathrm{Na}^{+}$current seen by ROS may cause a reduction in $\mathrm{CV}$ and provide substrate for reentry. ROS can downregulate cardiac sodium channels and mitochondrial antioxidants can reverse this effect [36]. This can also provide a substrate for arrhythmia in a similar fashion that happens in Brugada syndrome [37-39].

ROS may also alter intracellular $\mathrm{Ca}^{2+}$ handling in a way that generates arrhythmia. ROS may stimulate the L-type $\mathrm{Ca}^{2+}$ current, which can facilitate EAD [40]. In addition, hydroxyl radicals increase the open probability of cardiac ryanodine receptors, which control the $\mathrm{Ca}^{2+}$ release from the sarcoplasmic reticulum (SR) to the cytoplasm [41]. Abnormal $\mathrm{Ca}^{2+}$ release from SR during diastole may result in formation and propagation of DADs [42, 43]. Even a brief exposure to $\mathrm{OH}^{-}$significantly decreases SR Ca ${ }^{2+}$ uptake, which leads to an increased $\mathrm{Ca}^{2+}$ level in myocytes during diastole [44]. This short-term effect on $\mathrm{Ca}^{2+}$ transport is likely due to the $\mathrm{OH}^{-}$-mediated peroxidation of lipid membranes and protein sulfhydryl formation, which leads to an indirect effect on the SR $\mathrm{Ca}^{2+}$ transporter [44]. Increase in intracellular levels of $\mathrm{Ca}^{2+}$ can then translate to an inward current by sodium-calcium exchanger (NCX) action. In addition ROS may increase directly NCX activity [43].

In addition to the cardiac $\mathrm{Na}^{+}$current and intracellular $\mathrm{Ca}^{2+}$ handling, oxidative stress affects also cardiac potassium currents. ROS may inhibit $\mathrm{K}_{\mathrm{ATP}}$ channels [45] and downregulates $I_{\text {to }}[46,47]$. These effects of ROS and its possible suppression of $I_{\mathrm{Kr}}$ and $I_{\mathrm{Ks}}$ [48] can potentially decrease the repolarization reserve, prolong the APD, and facilitate triggered activity.

In summary, ROS can affect all major ionic currents with increases in the late $\mathrm{Na}^{+}$current, L-type $\mathrm{Ca}^{2+}$ current, leak of $\mathrm{Ca}^{2+}$ from SR, and NCX activity. ROS decrease peak sodium current and SERCA-mediated SR $\mathrm{Ca}^{2+}$ uptake. All these changes are likely to increase intracellular $\mathrm{Ca}^{2+}$ levels, 
prolong the $\mathrm{APD}$, reduce of $\mathrm{CV}$, and facilitate triggered activity and reentry.

\section{Oxidative Stress and Cell Coupling}

Oxidative stress promotes myocardial fibrosis $[49,50]$. Biophysical properties of the extracellular matrix (ECM) are important factors that can affect the propagation of the action potential in the heart. For example, increased collagen deposition in the ECM, which is seen in increased myocardial fibrosis and scar tissue formation after myocardial infarction, may provide a barrier to the AP propagation and contribute to reentry [51]. In addition, collagen deposition may reduce electrical coupling between myocytes and facilitate focal activities by reducing the sink-to-source effect in the region of the heart [14]. Proliferation of fibroblasts and their transformation to myofibroblasts may be associated with myocytefibroblast coupling, which is potentially arrhythmogenic via increased ectopic activity [52].

Another important factor that affects electrical coupling of myocytes is gap junction function, and oxidative stress impairs gap junction conduction [30, 53, 54]. Gap junctions are channels in all compartments of the heart that form the conduction pathways between cells allowing for an electrical syncytium. Connexin $43(\mathrm{Cx} 43)$ is the major component of gap junctions in the ventricular myocytes, and it is one of the important connexins in the atria. Cx43 is decreased in human heart failure, a condition that is associated with significantly increased ROS levels and increased risk of arrhythmia [24, 55-57]. In cardiac angiotensin II activation and mitochondrial oxidative stress mouse models, ROS elevation significantly decreases $\mathrm{Cx} 43$ levels, impairs gap junction conduction, and results in spontaneous and pacing induced arrhythmia $[31,32,58,59]$. Treatments with a mitochondria-targeted antioxidant and angiotensin receptor blockers prevent the gap junctional remodeling and arrhythmias, supporting a key role for oxidative stress in $\mathrm{Cx} 43$ remodeling and impairing electrical coupling between myocytes [30-32].

\section{Molecular Mechanisms of ROS-Induced Arrhythmia}

While ROS seems to be able to cause arrhythmias, at least when externally supplied, and there are some possible alterations that can explain the arrhythmogenic substrate created by ROS, more effort and focus are required to explore the molecular mechanisms by which ROS result in those abnormalities. These mechanisms may involve the effect of ROS on genes, transcriptional regulation, protein trafficking, and posttranslational modifications. There are examples of studies that described novel molecular mechanisms for ROSinduced arrhythmia, which may result in discovering potentially new antiarrhythmic targets; however, there are much more research needed in this area.

The molecular mechanism by which ROS affect the cardiac $\mathrm{Na}^{+}$current and how the $\mathrm{Na}^{+}$current reduction can be prevented will be important steps toward designing new and effective antiarrhythmic drugs. Abnormal splicing of cardiac sodium channel mRNA is a possible mechanism for the decreased sodium current in arrhythmia. The splicing factors RBM25 and LUC7L3 are elevated in human heart failure tissue and mediate truncation of SCN5A mRNA in both Jurkat cells and human embryonic stem cell-derived cardiomyocytes [60]. RBM25/LUC7L3-mediated abnormal SCN5A mRNA splicing reduces $\mathrm{Na}^{+}$channel current to a range known to cause sudden cardiac death [61]. It has been shown that angiotensin II and hypoxia, known to cause elevation in ROS levels [62-64], are associated with the aforementioned splicing factor abnormalities resulting in a $\mathrm{Na}^{+}$ current reduction in the heart [60]. Another mechanism by which ROS may affect cardiac sodium current is probably via protein kinase $\mathrm{C}(\mathrm{PKC})$. It has been shown that mitochondrial ROS causes a reduction in cardiac sodium current and that effect can be prevented by inhibition of PKC [36]. In addition, c-Src inhibition can recover cardiac $\mathrm{Na}^{+}$current to normal in a mouse model of manganese superoxide dismutase deficient with elevated mitochondrial ROS, which suggests that c-Src partially mediates the effect of ROS on cardiac $\mathrm{Na}^{+}$current reduction [59].

$\mathrm{Ca}^{2+} / \mathrm{CaM}$-dependent kinase II (CaMKII) can be activated by ROS, and its activation probably mediates several of the ROS-induced arrhythmogenic effects [65]. If CaMKII is activated under prooxidant conditions, two methionine residues become oxidized, and the sustained activation of CaMKII, independent of its binding to $\mathrm{Ca}^{2+} / \mathrm{CaM}$, occurs [66]. Pretreatment of hypertensive rat hearts with a CaMKIIinhibitor KN-93 prevents VT inducibility during oxidative stress [67]. These findings are supported by both patchclamp and $\mathrm{Ca}^{2+}$-imaging studies, which demonstrate that the oxidative-stress-induced activation of CaMKII causes arrhythmias [68]. Several recent studies have linked the use of CaMKII inhibitors to a decrease in catecholaminergic polymorphic ventricular tachycardia $[69,70]$.

Other possible arrhythmogenic mechanisms by which CaMKII activation exerts arrhythmic effects include RyR phosphorylation and activation under oxidative stress [71, 72]. An increase in the open probability of RyR is thought to be mediated by CaMKII activation [42]. In addition, CaMKII has been shown to shift the voltage dependence of $\mathrm{Na}^{+}$channel availability by approximately $+5 \mathrm{mV}$, to hasten recovery from inactivation, and to increase late $\mathrm{Na}^{+}$current in cardiomyocytes [73]. CaMKII plays an important role in Ltype $\mathrm{Ca}^{2+}$ channel facilitation, the $\mathrm{Ca}^{2+}$-dependent augmentation of $\mathrm{Ca}^{2+}$ current $\left(I_{\mathrm{CaL}}\right)$ exhibited during rapid repeated depolarization [74]. In addition, CaMKII has been identified recently as one of the mediators of fibroblast proliferation in response to angiotensin II [75]. Because CaMKII is a relatively indiscriminate kinase, it is very possible that other mechanisms are involved in the genesis of arrhythmia by CaMKII activation under oxidative stress.

\section{Conclusion}

Ventricular and atrial arrhythmias place considerable burden on the healthcare system. Currently, available therapies for arrhythmia have certain limitations. In order to identify 
TABLE 1: A summary of mechanisms of oxidative stress induced arrhythmia and potential therapeutic targets.

\begin{tabular}{|c|c|}
\hline \multirow{6}{*}{ Affected ion channels } & $\begin{array}{l}\mathrm{Na}^{+} \text {current reduction (via PKC and c-Src, also via abnormal splicing) } \Rightarrow \text { reduction in } \\
\text { conduction velocity }\end{array}$ \\
\hline & KATP inhibition $\Rightarrow$ repolarization abnormality \\
\hline & NCX activation $\Rightarrow$ increasing inward current and facilitating afterdepolarization \\
\hline & $I_{\mathrm{to}}, I_{\mathrm{Kr}}, I_{\mathrm{Ks}}$ inhibition $\Rightarrow$ abnormal repolarization \\
\hline & $\begin{array}{l}\text { Increase in inward } \mathrm{Ca}^{++} \text {current (direct or via CaMKII activation) } \Rightarrow \text { facilitating } \\
\text { afterdepolarization }\end{array}$ \\
\hline & Increase in late $\mathrm{Na}^{+}$current $\Rightarrow$ facilitating afterdepolarization \\
\hline \multirow{2}{*}{ Effect on intracellular $\mathrm{Ca}^{++}$handling } & $\begin{array}{l}\text { Impairment of SERCA } \Rightarrow \text { increase intracellular } \mathrm{Ca}^{++} \text {levels } \Rightarrow \text { facilitating } \\
\text { afterdepolarization }\end{array}$ \\
\hline & $\begin{array}{l}\text { Affecting RyR receptor (via CaMKII activation) } \Rightarrow \text { leakiness of } \mathrm{SR} \Rightarrow \text { increase } \\
\text { intracellular } \mathrm{Ca}^{++} \text {levels } \Rightarrow \text { facilitating afterdepolarization }\end{array}$ \\
\hline Effect on myocyte-myocyte coupling & Affecting assembling of $\mathrm{Cx} 43$ at gap junctions $\Rightarrow$ reduction in conduction velocity \\
\hline Effect on extracellular matrix & $\begin{array}{l}\text { Activating fibrotic process (via TGF- } \beta \text { ) } \Rightarrow \text { reduction in conduction velocity and impairec } \\
\text { myocyte-myocyte coupling due to collagen deposition }\end{array}$ \\
\hline
\end{tabular}

CaMKII: $\mathrm{Ca}^{2+} /$ calmodulin-dependent protein kinases II; Cx43: connexin 43; $\mathrm{NCX}: \mathrm{Na}^{+} / \mathrm{Ca}^{2+}$ exchanger; RyR: ryanodine receptor; SERCA: sarco/endoplasmic reticulum $\mathrm{Ca}^{++}$- ATPase; TGF- $\beta$ : Transforming Growth Factor- $\beta$.

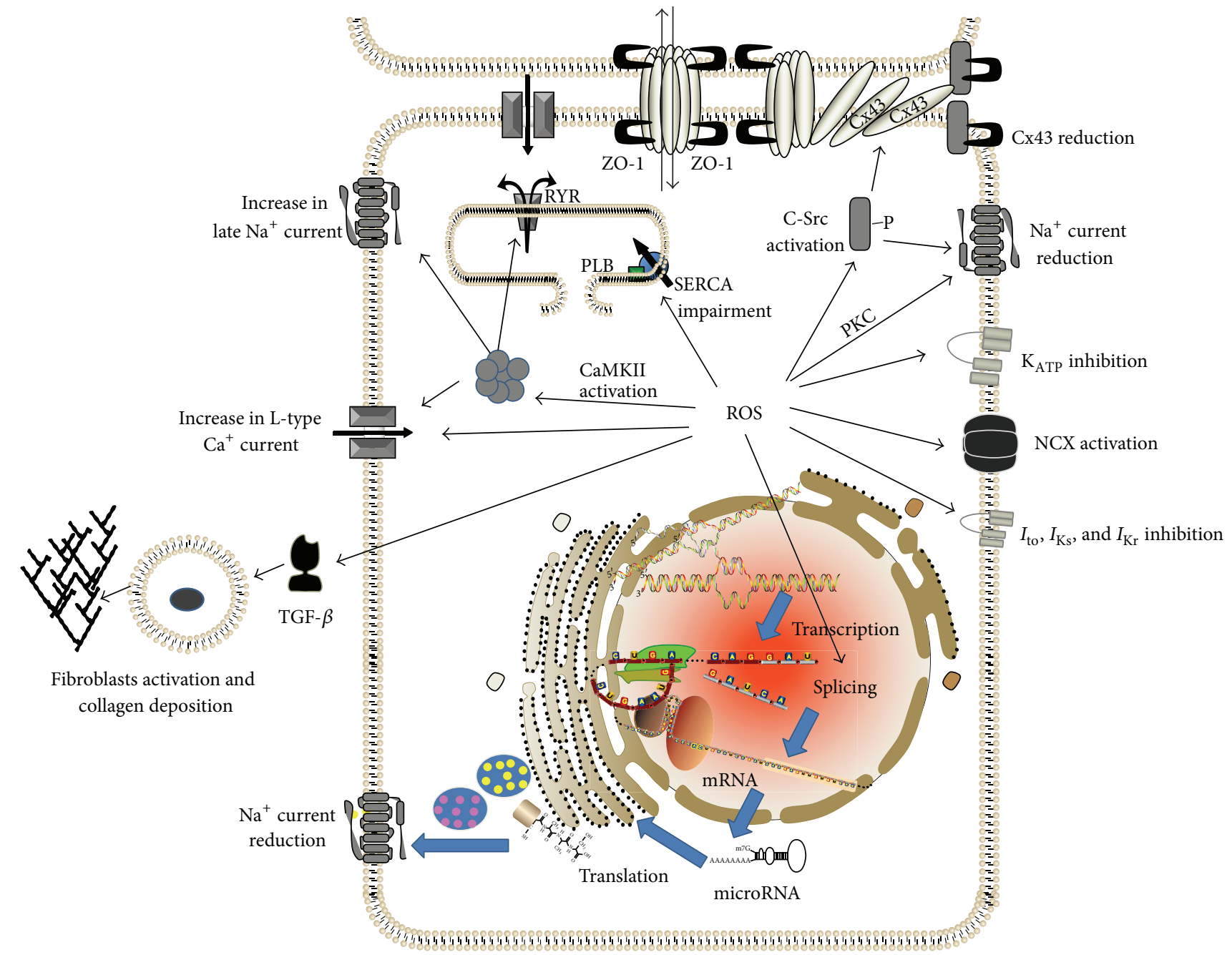

FIGURE 1: Schematic review of some of the important known mechanisms by which excess ROS may induce arrhythmia. Activation of CaMKII, c-Src, and PKC may mediate several important effects of ROS on ionic currents resulting in arrhythmia. In addition, ROS adversely affect splicing of mRNA of cardiac sodium channels resulting in abnormal truncated cardiac sodium channel proteins and a reduction in normal sodium channels. ROS also increase fibrosis and impair gap junction conduction, resulting in reduced myocyte coupling. Abnormal splicing, activation of CaMKII, c-Src, and PKC are among emerging new antiarrhythmic therapeutic targets. CaMKII: $\mathrm{Ca}^{2+} / \mathrm{calmodulin}^{2}$-dependent protein kinases II; CX43: connexin 43; NCX: $\mathrm{Na}^{+} / \mathrm{Ca}^{2+}$ exchanger; PLB: phospholamban; ROS: reactive oxygen species; RYR: ryanodine receptor; SERCA: sarco-/endoplasmic reticulum $\mathrm{Ca}^{2+}$-ATPase; TGF- $\beta$ : Transforming Growth Factor- $\beta$; ZO-1: Zonula Occludens-1. 
new, effective therapeutic targets for treatment of arrhythmia, mechanisms of the genesis of arrhythmia should be further explored. One possible upstream therapeutic target for treatment of arrhythmia is oxidative stress. It has been shown that excess amount of ROS can result in both reentry and focal activity by modifying many of the ionic currents in cardiomyocytes, cardiomyocyte coupling, and important elements of the extracellular matrix (Figure 1 and Table 1). Molecular mechanisms by which ROS exert those effects are the key areas under investigation. Activation of CaMKII, cSrc, PKC, and abnormal splicing of cardiac sodium channels are among the emerging new therapeutic targets.

\section{List of Abbreviations}

AF: Atrial fibrillation

APD: Action potential duration

CaMKII: $\mathrm{Ca}^{2+} /$ calmodulin-dependent protein kinases II

Cx43: $\quad$ Connexin 43

CV: $\quad$ Conduction velocity

DAD: Delayed afterdepolarization

EAD: Early afterdepolarization

ICD: Implantable cardioverter defibrillator

NCX: $\quad \mathrm{Na}^{+} / \mathrm{Ca}^{2+}$ exchanger

PLB: Phospholamban

ROS: $\quad$ Reactive oxygen species

RyR: Ryanodine receptor

SERCA: Sarco-/endoplasmic reticulum $\mathrm{Ca}^{2+}$-ATPase

SCA: Sudden cardiac arrest

SCD: $\quad$ Sudden cardiac death

TGF- $\beta$ : Transforming Growth Factor- $\beta$

VT: $\quad$ Ventricular tachycardia

VF: Ventricular fibrillation

ZO-1: Zonula Occludens-1.

\section{Conflict of Interests}

Ali A. Sovari has the pending patent: Mitochondria Antioxidants for Prevention of Sudden Death by Raising Connexin 43 Levels (Application no. 61/503,096).

\section{References}

[1] K. D. Kochanek, S. E. Kirmeyer, J. A. Martin, D. M. Strobino, and B. Guyer, "Annual summary of vital statistics: 2009," Pediatrics, vol. 129, no. 2, pp. 338-348, 2012.

[2] M. Rubart and D. P. Zipes, "Mechanisms of sudden cardiac death," The Journal of Clinical Investigation, vol. 115, no. 9, pp. 2305-2315, 2005.

[3] W. M. Feinberg, J. L. Blackshear, A. Laupacis, R. Kronmal, and R. G. Hart, "Prevalence, age distribution, and gender of patients with atrial fibrillation. Analysis and implications," Archives of Internal Medicine, vol. 155, pp. 469-473, 1995.

[4] P. A. Wolf, R. D. Abbott, and W. B. Kannel, "Atrial fibrillation as an independent risk factor for stroke: the Framingham Study," Stroke, vol. 22, no. 8, pp. 983-988, 1991.

[5] C. D. Furberg, B. M. Psaty, T. A. Manolio, J. M. Gardin, V. E. Smith, and P. M. Rautaharju, "Prevalence of atrial fibrillation in elderly subjects (the Cardiovascular Health Study)," The American Journal of Cardiology, vol. 74, no. 3, pp. 236-241, 1994.

[6] B. M. Psaty, T. A. Manolio, L. H. Kuller et al., "Incidence of and risk factors for atrial fibrillation in older adults," Circulation, vol. 96, no. 7, pp. 2455-2461, 1997.

[7] P. A. Wolf, R. D. Abbott, and W. B. Kannel, "Atrial fibrillation: a major contributor to stroke in the elderly. The Framingham study," Archives of Internal Medicine, vol. 147, no. 9, pp. 15611564, 1987.

[8] A. D. Krahn, J. Manfreda, R. B. Tate, F. A. L. Mathewson, and T. E. Cuddy, "The natural history of atrial fibrillation: incidence, risk factors, and prognosis in the manitoba follow-up study," The American Journal of Medicine, vol. 98, no. 5, pp. 476-484, 1995.

[9] The Cardiac Arrhythmia Suppression Trial (CAST) Investigators, "Preliminary report: effect of encainide and flecainide on mortality in a randomized trial of arrhythmia suppression after myocardial infarction," The New England Journal of Medicine, vol. 321, pp. 406-412, 1989.

[10] K. K. Anthony and V. F. Mauro, "Rate versus rhythm control in atrial fibrillation," Annals of Pharmacotherapy, vol. 38, no. 5, pp. 839-844, 2004.

[11] D. M. Roden, "Antiarrhythmic drugs: from mechanisms to clinical practice," Heart, vol. 84, no. 3, pp. 339-346, 2000.

[12] R. Lazzara, "Antiarrhythmic drugs and torsade de pointes," European Heart Journal, vol. 14, supplement H, pp. 88-92, 1993.

[13] D. Sato, L.-H. Xie, A. A. Sovari et al., "Synchronization of chaotic early afterdepolarizations in the genesis of cardiac arrhythmias," Proceedings of the National Academy of Sciences of the United States of America, vol. 106, no. 9, pp. 2983-2988, 2009.

[14] N. Morita, A. A. Sovari, Y. Xie et al., "Increased susceptibility of aged hearts to ventricular fibrillation during oxidative stress," The American Journal of Physiology-Heart and Circulatory Physiology, vol. 297, no. 5, pp. H1594-H1605, 2009.

[15] N. Ono, H. Hayashi, A. Kawase et al., "Spontaneous atrial fibrillation initiated by triggered activity near the pulmonary veins in aged rats subjected to glycolytic inhibition," The American Journal of Physiology-Heart and Circulatory Physiology, vol. 292, no. 1, pp. H639-H648, 2007.

[16] E. Wissner, W. G. Stevenson, and K.-H. Kuck, "Catheter ablation of ventricular tachycardia in ischaemic and non-ischaemic cardiomyopathy: where are we today? A clinical review," European Heart Journal, vol. 33, no. 12, pp. 1440-1450, 2012.

[17] G. D. Sanders, A. M. Bayoumi, V. Sundaram et al., "Costeffectiveness of screening for HIV in the era of highly active antiretroviral therapy," The New England Journal of Medicine, vol. 352, no. 6, pp. 570-585, 2005.

[18] R. J. Myerburg, R. Mitrani, A. Interian Jr., and A. Castellanos, "Interpretation of outcomes of antiarrhythmic clinical trials: design features and population impact," Circulation, vol. 97, no. 15, pp. 1514-1521, 1998.

[19] A. A. Sovari and S. C. Dudley, "Atrial fibrillation and oxidative stress," in Studies in Cardiovascular Disorders, H. Sauer, M. S. Ajay, and F. R. Laurindo, Eds., pp. 373-389, Humana Press, New York, NY, USA, 1st edition, 2010.

[20] R. B. Neuman, H. L. Bloom, I. Shukrullah et al., "Oxidative stress markers are associated with persistent atrial fibrillation," Clinical Chemistry, vol. 53, no. 9, pp. 1652-1657, 2007.

[21] C. A. Carnes, M. K. Chung, T. Nakayama et al., "Ascorbate attenuates atrial pacing-induced peroxynitrite formation and 
electrical remodeling and decreases the incidence of postoperative atrial fibrillation," Circulation research, vol. 89, no. 6, pp. E32-E38, 2001.

[22] M. Ozaydin, O. Peker, D. Erdogan et al., " $N$-acetylcysteine for the prevention of postoperative atrial fibrillation: a prospective, randomized, placebo-controlled pilot study," European Heart Journal, vol. 29, no. 5, pp. 625-631, 2008.

[23] Y. H. Kim, J. H. Lee, D. S. Lim et al., "Gene expression profiling of oxidative stress on atrial fibrillation in humans," Experimental and Molecular Medicine, vol. 35, no. 5, pp. 336-349, 2003.

[24] M. Canton, S. Menazza, F. L. Sheeran, P. P. de Laureto, F. Di Lisa, and S. Pepe, "Oxidation of myofibrillar proteins in human heart failure," Journal of the American College of Cardiology, vol. 57, no. 3, pp. 300-309, 2011.

[25] N. Morita, J. H. Lee, Y. Xie et al., "Suppression of re-entrant and multifocal ventricular fibrillation by the late sodium current blocker ranolazine," Journal of the American College of Cardiology, vol. 57, no. 3, pp. 366-375, 2011.

[26] H. D. Sesso, J. E. Buring, W. G. Christen et al., "Vitamins E and $\mathrm{C}$ in the prevention of cardiovascular disease in men: the Physicians' Health Study II randomized controlled trial," The Journal of the American Medical Association, vol. 300, no. 18, pp. 2123-2133, 2008.

[27] A. Beresewicz and M. Horackova, "Alterations in electrical and contractile behavior of isolated cardiomyocytes by hydrogen peroxide: possible ionic mechanisms," Journal of Molecular and Cellular Cardiology, vol. 23, no. 8, pp. 899-918, 1991.

[28] N. Morita, A. A. Sovari, Y. Xie et al., "Increased susceptibility of aged hearts to ventricular fibrillation during oxidative stress," American Journal of Physiology-Heart and Circulatory Physiology, vol. 297, no. 5, pp. H1594-H1605, 2009.

[29] A. A. Sovari, N. Vahdani, N. Morita, K. Roos, J. N. Weiss, and H. S. Karagueuzian, "Oxidative stress promotes ventricular fibrillation at early stages of hypertension: role of $\mathrm{Ca}^{2+} / \mathrm{CaM}$ kinase-II," Heart Rhythm, vol. 7, supplement, pp. PO3-PO92, 2010.

[30] A. A. Sovari, S. Iravanian, D. Mitchell et al., "Mitochondriatargeted antioxidant, mito-tempo, prevents angiotensin II mediated connexin 43 remodeling and sudden cardiac death," Journal of Investigative Medicine, vol. 59, pp. 692-730, 2011.

[31] S. Iravanian, A. A. Sovari, H. A. Lardin et al., "Inhibition of renin-angiotensin system (RAS) reduces ventricular tachycardia risk by altering connexin43," Journal of Molecular Medicine, vol. 89, no. 7, pp. 677-687, 2011.

[32] A. A. Sovari, S. Iravanian, E. Dolmatova et al., "Inhibition of cSrc tyrosine kinase prevents angiotensin II-mediated connexin43 remodeling and sudden cardiac death," Journal of the American College of Cardiology, vol. 58, no. 22, pp. 2332-2339, 2011.

[33] M. D. Christensen, W. Dun, P. A. Boyden, M. E. Anderson, P. J. Mohler, and T. J. Hund, "Oxidized calmodulin kinase II regulates conduction following myocardial infarction: a computational analysis," PLoS Computational Biology, vol. 5, no. 12, Article ID e1000583, 2009.

[34] Y. Song, J. C. Shryock, S. Wagner, L. S. Maier, and L. Belardinelli, "Blocking late sodium current reduces hydrogen peroxideinduced arrhythmogenic activity and contractile dysfunction," Journal of Pharmacology and Experimental Therapeutics, vol. 318, no. 1, pp. 214-222, 2006.

[35] L. L. Shang, S. Sanyal, A. E. Pfahnl et al., "NF- $\kappa$ B-dependent transcriptional regulation of the cardiac scn 5 a sodium channel by angiotensin II," The American Journal of Physiology-Cell Physiology, vol. 294, no. 1, pp. C372-C379, 2008.

[36] M. Liu, H. Liu, and S. C. Dudley Jr., "Reactive oxygen species originating from mitochondria regulate the cardiac sodium channel," Circulation Research, vol. 107, no. 8, pp. 967-974, 2010.

[37] P. Brugada, "Commentary on the Brugada ECG pattern: a marker of channelopathy, structural heart disease, or neither? Toward a unifying mechanism of the Brugada syndrome," Circulation: Arrhythmia and Electrophysiology, vol. 3, no. 3, pp. 280-282, 2010.

[38] A. A. Sovari, M. A. Prasun, and A. G. Kocheril, "ST segment elevation on electrocardiogram: the electrocardiographic pattern of Brugada syndrome," MedGenMed Medscape General Medicine, vol. 9, no. 3, article 59, 2007.

[39] A. A. Sovari, M. A. Prasun, A. G. Kocheril, and R. Brugada, "Brugada syndrome unmasked by pneumonia," Texas Heart Institute Journal, vol. 33, no. 4, pp. 501-504, 2006.

[40] G. P. Thomas, S. M. Sims, M. A. Cook, and M. Karmazyn, "Hydrogen peroxide-induced stimulation of L-type calcium current in guinea pig ventricular myocytes and its inhibition by adenosine A1 receptor activation," Journal of Pharmacology and Experimental Therapeutics, vol. 286, no. 3, pp. 1208-1214, 1998.

[41] K. Anzai, K. Ogawa, A. Kuniyasu, T. Ozawa, H. Yamamoto, and H. Nakayama, "Effects of hydroxyl radical and sulfhydryl reagents on the open probability of the purified cardiac ryanodine receptor channel incorporated into planar lipid bilayers," Biochemical and Biophysical Research Communications, vol. 249, no. 3, pp. 938-942, 1998.

[42] X. Ai, J. W. Curran, T. R. Shannon, D. M. Bers, and S. M. Pogwizd, " $\mathrm{Ca}^{2+} /$ calmodulin-dependent protein kinase modulates cardiac ryanodine receptor phosphorylation and sarcoplasmic reticulum $\mathrm{Ca}^{2+}$ leak in heart failure," Circulation Research, vol. 97, pp. 1314-1322, 2005.

[43] D. M. Bers and S. Despa, "Cardiac myocytes $\mathrm{Ca}^{2+}$ and $\mathrm{Na}^{+}$regulation in normal and failing hearts," Journal of Pharmacological Sciences, vol. 100, no. 5, pp. 315-322, 2006.

[44] T. E. Morris and P. V. Sulakhe, "Sarcoplasmic reticulum $\mathrm{Ca}^{2+}$ pump dysfunction in rat cardiomyocytes briefly exposed to hydoxyl radicals," Free Radical Biology \& Medicine, vol. 22, no. 1-2, pp. 37-47, 1997.

[45] Y. Yang, W. Shi, N. Cui, Z. Wu, and C. Jiang, "Oxidative stress inhibits vascular $\mathrm{K}_{\mathrm{ATP}}$ channels by $S$-glutathionylation," The Journal of Biological Chemistry, vol. 285, no. 49, pp. 3864138648, 2010.

[46] M. Seddon, Y. H. Looi, and A. M. Shah, "Oxidative stress and redox signalling in cardiac hypertrophy and heart failure," Heart, vol. 93, no. 8, pp. 903-907, 2007.

[47] C. X. C. Santos, N. Anilkumar, M. Zhang, A. C. Brewer, and A. M. Shah, "Redox signaling in cardiac myocytes," Free Radical Biology and Medicine, vol. 50, no. 7, pp. 777-793, 2011.

[48] Y. Zhang, J. Xiao, H. Wang et al., "Restoring depressed HERG $\mathrm{K}^{+}$channel function as a mechanism for insulin treatment of abnormal QT prolongation and associated arrhythmias in diabetic rabbits," American Journal of Physiology-Heart and Circulatory Physiology, vol. 291, no. 3, pp. H1446-H1455, 2006.

[49] A. Cui, Q. Ye, R. Sarria, S. Nakamura, J. Guzman, and U. Costabel, "N-acetylcysteine inhibits TNF- $\alpha$, sTNFR, and TGF$\beta 1$ release by alveolar macrophages in idiopathic pulmonary fibrosis in vitro," Sarcoidosis Vasculitis and Diffuse Lung Diseases, vol. 26, no. 2, pp. 147-154, 2009.

[50] K. Koli, M. Myllärniemi, J. Keski-Oja, and V. L. Kinnula, "Transforming growth factor- $\beta$ activation in the lung: focus on 
fibrosis and reactive oxygen species," Antioxidants and Redox Signaling, vol. 10, no. 2, pp. 333-342, 2008.

[51] J. M. T. de Bakker, F. J. L. van Capelle, M. J. Janse et al., "Reentry as a cause of ventricular tachycardia in patients with chronic ischemic heart disease: electrophysiologic and anatomic correlation," Circulation, vol. 77, no. 3, pp. 589-606, 1988.

[52] M. Miragoli, N. Salvarani, and S. Rohr, "Myofibroblasts induce ectopic activity in cardiac tissue," Circulation Research, vol. 101, no. 8, pp. 755-758, 2007.

[53] E.-M. Jeong, M. Liu, M. Sturdy et al., "Metabolic stress, reactive oxygen species, and arrhythmia," Journal of Molecular and Cellular Cardiology, vol. 52, no. 2, pp. 454-463, 2012.

[54] V. M. Berthoud and E. C. Beyer, "Oxidative stress, lens gap junctions, and cataracts," Antioxidants and Redox Signaling, vol. 11, no. 2, pp. 339-353, 2009.

[55] C. Banfi, M. Brioschi, S. Barcella et al., "Oxidized proteins in plasma of patients with heart failure: role in endothelial damage," European Journal of Heart Failure, vol. 10, no. 3, pp. 244-251, 2008.

[56] A. F. Bruce, S. Rothery, E. Dupont, and N. J. Severs, "Gap junction remodelling in human heart failure is associated with increased interaction of connexin 43 with ZO-1," Cardiovascular Research, vol. 77, no. 4, pp. 757-765, 2008.

[57] R. R. Kaprielian, M. Gunning, E. Dupont et al., "Downregulation of immunodetectable connexin 43 and decreased gap junction size in the pathogenesis of chronic hibernation in the human left ventricle," Circulation, vol. 97, no. 7, pp. 651-660, 1998.

[58] A. A. Sovari, S. Iravanian, D. Mitchell et al., "Mitochondriatargeted antioxidant, Mito-TEMPO, prevents angiotensin II mediated connexin 43 remodeling and sudden cardiac death," Journal of Investigative Medicine, vol. 59, pp. 692-730, 2011.

[59] A. A. Sovari, E.-M. Jeong, E. Dolmatova et al., "c-Src tyrosine kinase mediates the effect of mitochondrial oxidative stress on gap junctional remodeling and ventricular tachycardia," Circulation, vol. 124, Article ID A14385, 2011.

[60] G. Gao, A. Xie, S.-C. Huang et al., "Role of RBM25/LUC7L3 in abnormal cardiac sodium channel splicing regulation in human heart failure," Circulation, vol. 124, no. 10, pp. 1124-1131, 2011.

[61] E. Burashnikov, R. Pfeifer, M. Borggrefe et al., "Mutations in the cardiac L-type calcium channel associated with inherited sudden cardiac death syndromes," Circulation, vol. 120, article S573, 2009.

[62] R. S. Stearman, L. Dwyer-Nield, L. Zerbe et al., "Analysis of orthologous gene expression between human pulmonary adenocarcinoma and a carcinogen-induced murine model," The American Journal of Pathology, vol. 167, no. 6, pp. 1763-1775, 2005.

[63] R. M. A. van de Wal, H. W. M. Plokker, D. J. A. Lok et al., "Determinants of increased angiotensin II levels in severe chronic heart failure patients despite ACE inhibition," International Journal of Cardiology, vol. 106, no. 3, pp. 367-372, 2006.

[64] L. Køber, C. Torp-Pedersen, J. E. Carlsen et al., "A clinical trial of the angiotensin-converting-enzyme inhibitor trandolapril in patients with left ventricular dysfunction after myocardial infarction," The New England Journal of Medicine, vol. 333, no. 25, pp. 1670-1676, 1995.

[65] B. Hoch, R. Meyer, R. Hetzer, E.-G. Krause, and P. Karczewski, "Identification and expression of $\delta$-isoforms of the multifunctional $\mathrm{Ca}^{2+} /$ calmodulin-dependent protein kinase in failing and nonfailing human myocardium," Circulation Research, vol. 84, pp. 713-721, 1999.

[66] J. R. Erickson, M.-L. A. Joiner, X. Guan et al., "A dynamic pathway for calcium-independent activation of CaMKII by methionine oxidation," Cell, vol. 133, no. 3, pp. 462-474, 2008.

[67] A. A. Sovari, N. Morita, J. N. Weiss, and H. Karagueuzian, "Oxidative stress promotes ventricular fibrillation in spontaneously hypertensive rats by a $\mathrm{Ca}^{2+} / \mathrm{CaM}$ dependent kinase-II signaling pathway," Journal of the American College of Cardiology, vol. 53, pp. A101-A102, 2009.

[68] L.-H. Xie, F. Chen, H. S. Karagueuzian, and J. N. Weiss, "Oxidative stress-induced afterdepolarizations and calmodulin kinase II signaling," Circulation Research, vol. 104, no. 1, pp. 7986, 2009.

[69] J. Ke, C.-T. Zhang, Y.-X. Ma et al., "The effects of calmodulin kinase II inhibitor on ventricular arrhythmias in rabbits with cardiac hypertrophy," Zhonghua Xin Xue Guan Bing Za Zhi, vol. 35, no. 1, pp. 33-36, 2007.

[70] U. Mohamed, C. Napolitano, and S. G. Priori, "Molecular and electrophysiological bases of catecholaminergic polymorphic ventricular tachycardia," Journal of Cardiovascular Electrophysiology, vol. 18, no. 7, pp. 791-797, 2007.

[71] D. B. Witcher, R. J. Kovacs, H. Schulman, D. C. Cefali, and L. R. Jones, "Unique phosphorylation site on the cardiac ryanodine receptor regulates calcium channel activity," The Journal of Biological Chemistry, vol. 266, no. 17, pp. 11144-11152, 1991.

[72] X. H. T. Wehrens, S. E. Lehnart, S. R. Reiken, and A. R. Marks, " $\mathrm{Ca}^{2+} /$ calmodulin-dependent protein kinase II phosphorylation regulates the cardiac ryanodine receptor," Circulation Research, vol. 94, pp. e61-e70, 2004.

[73] T. Aiba, G. G. Hesketh, T. Liu et al., " $\mathrm{Na}^{+}$channel regulation by $\mathrm{Ca}^{2+} /$ calmodulin and $\mathrm{Ca}^{2+} /$ calmodulin-dependent protein kinase II in guinea-pig ventricular myocytes," Cardiovascular Research, vol. 85, no. 3, pp. 454-463, 2010.

[74] Y. L. Hashambhoy, R. L. Winslow, and J. L. Greenstein, "CaMKII-induced shift in modal gating explains L-type $\mathrm{Ca}^{2+}$ current facilitation: a modeling study," Biophysical Journal, vol. 96, no. 5, pp. 1770-1785, 2009.

[75] F. Bellocci, L. M. Biasucci, G. F. Gensini et al., "Prognostic role of post-infarction C-reactive protein in patients undergoing implantation of cardioverter-defibrillators: design of the Creactive protein Assessment after Myocardial Infarction to GUide Implantation of DEfibrillator (CAMI GUIDE) study," Journal of Cardiovascular Medicine, vol. 8, no. 4, pp. 293-299, 2007. 


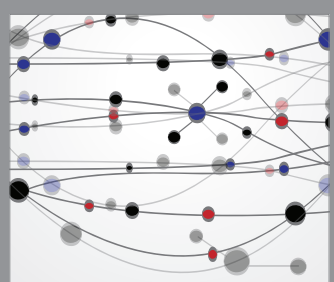

The Scientific World Journal
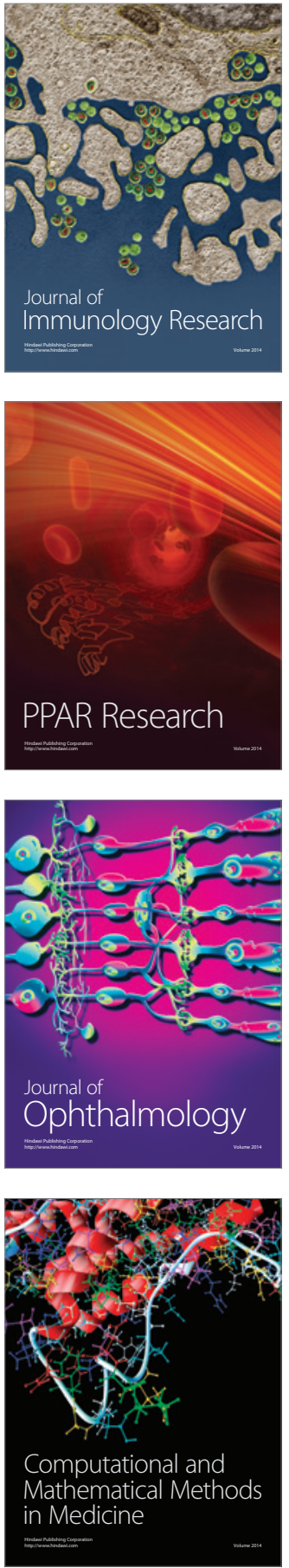

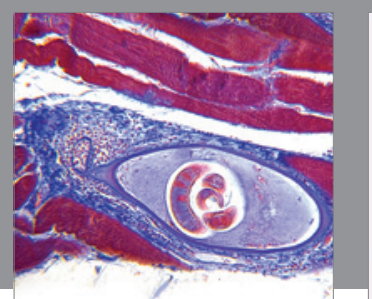

Gastroenterology Research and Practice

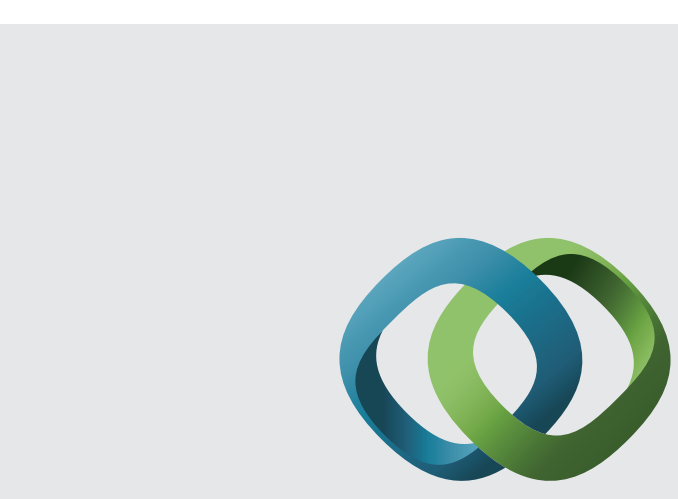

\section{Hindawi}

Submit your manuscripts at

http://www.hindawi.com
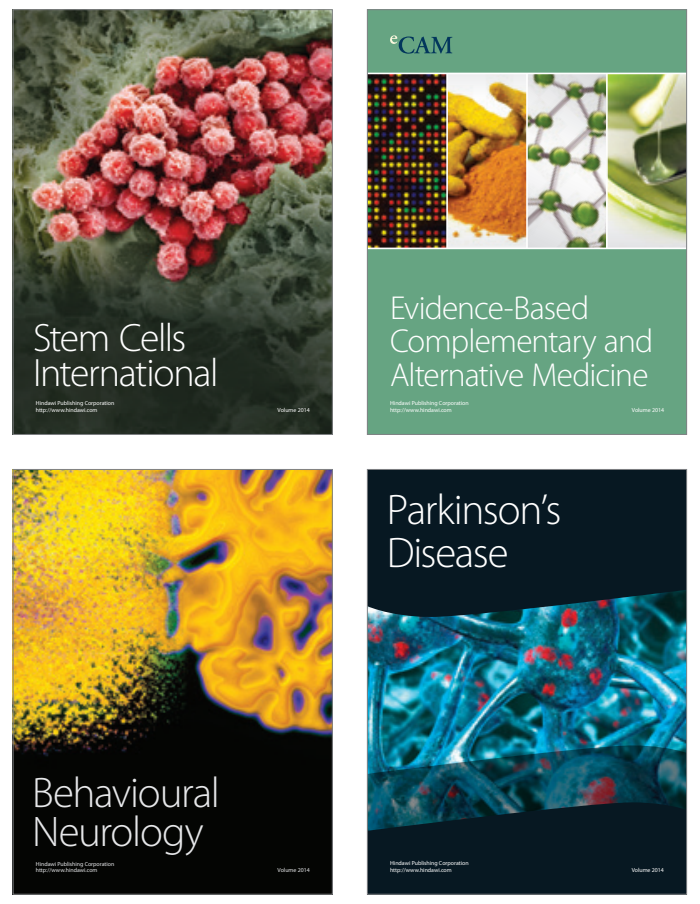
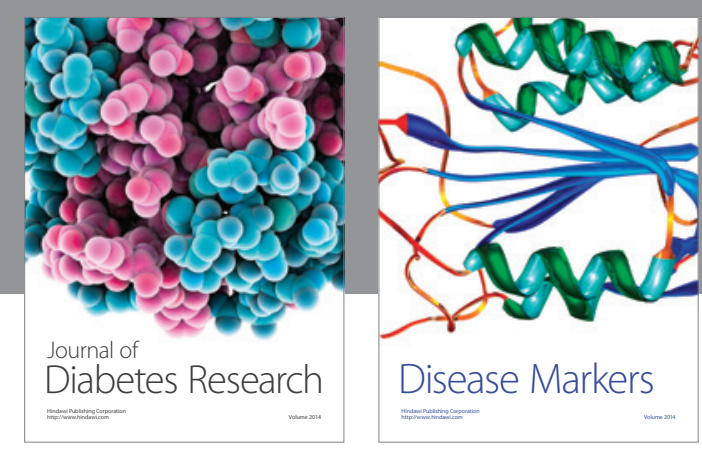

Disease Markers
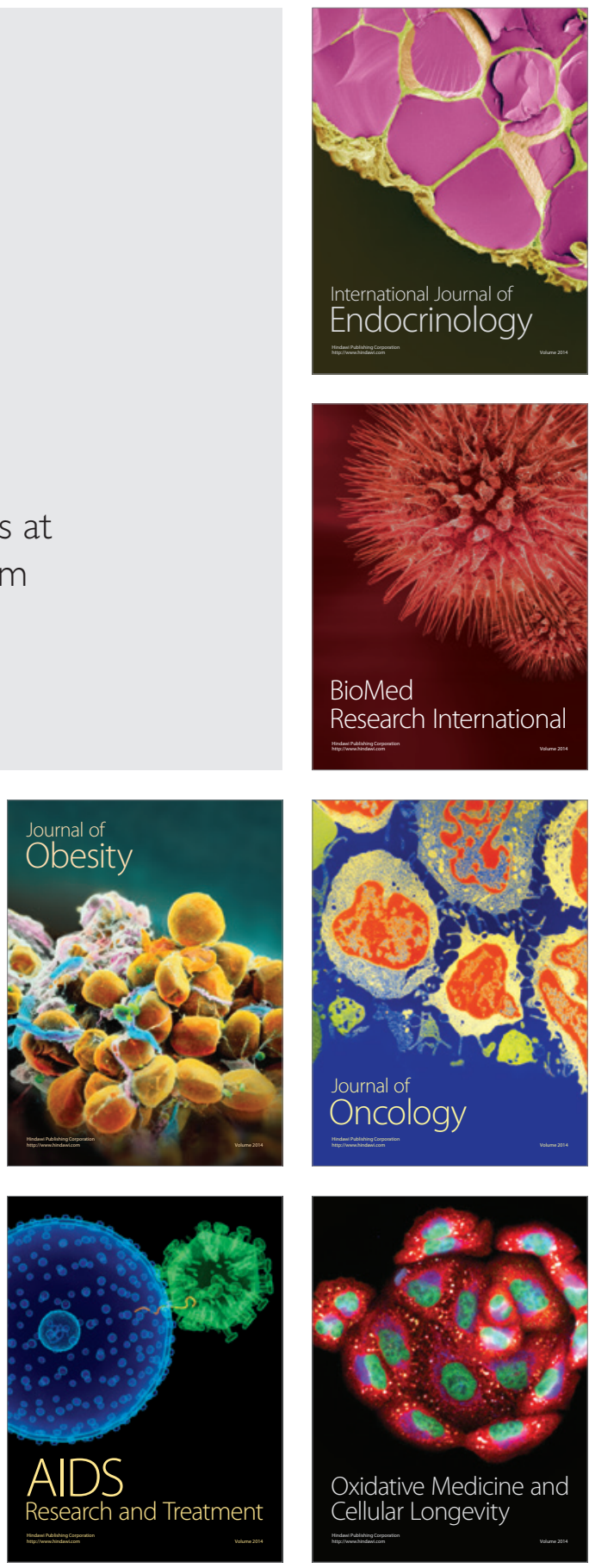